\title{
Changes in post-operative renal function and coagulation profile after hydroxyethyl starch administration in patients undergoing orthopedic hip surgery under spinal anesthesia
}

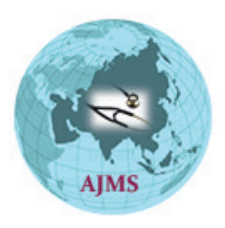

\author{
Kirti Kamal' ${ }^{1}$, Monika Bhandari ${ }^{2}$, Priyanka Bansal ${ }^{3}$, Geeta Ahlawat ${ }^{4}$, Renu Bala ${ }^{5}$, \\ Diya Aggrawal ${ }^{6}$ \\ 1,4,5 Professor, 2,6 Junior Resident, ${ }^{3}$ Associate Professor, Department of Anaesthesiology, Pandit Bhagwat Dayal Sharma \\ Post Graduate Institute of Medical Sciences, Rohtak, Haryana, India
}

A B S TR A C T

Background: Hydroxyethyl starch solutions which have been introduced some three decades ago, have been extensively used for treatment of intraoperative hypovolaemia. Aims and Objectives: The present prospective study was conducted to study changes in post-operative renal function and coagulation profile in patients undergoing orthopedic hip surgery under spinal anesthesia after coloading with 6\% HES 130/0.4. Materials and Methods: Seventy patients, aged between 50 and 80 years, of either sex, belonging to ASA physical Status I and II, scheduled for orthopedic hip surgery under spinal anesthesia were included in the study. As per the group allocation, coloading was done with $7.5 \mathrm{mlkg}^{-1}$ of either Group RL or $6 \% 130 / 0.4$ Group HES during the $1^{\text {st }} \mathrm{h}$ of surgery. Venous samples were withdrawn before the day of surgery, on the day of surgery, and on the $3^{\text {rd }}$ day of surgery. Results: No statistically significant difference between renal and coagulation profile was found among groups. Conclusion: Thus, we recommend using tetrastarch $16 \%$ HES 130/0.4) for intraoperative hypovolemia in elderly patients with normal renal function and coagulation profile undergoing orthopedic hip surgery.

Key words: Coagulation; Crystalloids; Hydroxyethyl starch solutions; Renal function; Tetrastarch; Hypovolemia; Acute kidney injury

\section{Access this article online}

Website:

http://nepjol.info/index.php/AJMS DOI: 10.3126/ajms.v12i11.39496

E-ISSN: 2091-0576

P-ISSN: $2467-9100$

Copyright (c) 2021 Asian Journal of Medical Sciences

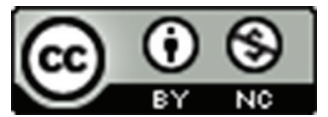

This work is licensed under a Creative Commons Attribution-NonCommercial 4.0 International License.

\section{INTRODUCTION}

Hydroxyethyl starch solutions (HESs) which have been introduced some three decades ago as an alternative to traditional volume expanders are increasingly being used for the treatment of intraoperative hypovolaemia. Worldwide, 1.6 million patients suffer from hip fracture every year, and this number has increased by $25 \%$ every decade as the population continues to grow. Hip fracture has devastating consequences in elderly patients and thus is associated with a poor outcome. These elderly patients with hip fracture remain a medical challenge for the anesthesiologist, mainly because of the frequent and numerous comorbidities encountered and high prevalence of preexisting medical conditions in this population. There is considerable blood loss during these surgeries and thus intraoperative intravascular fluid optimization becomes very significant for which either crystalloids or colloids can be given. ${ }^{2}$

Colloids are an alternative to the frequently used crystalloids, with highly variable use. They are considered to have a greater intravascular persistence compared to crystalloids. Moreover, resuscitation with crystalloids requires more fluid and results in more edema. However, colloids also have adverse effects on renal function and coagulation profile of patients. ${ }^{3}$ There has always been a 
controversy around the superiority of colloids regarding hemodynamic optimization and about possible detrimental effects, especially among elderly population. ${ }^{2}$

Hydroxyethyl starch (HES) is a chemically modified polysaccharide composed of long chains of branched glucose polymers substituted periodically by hydroxyethyl radicals which resist enzymatic degradation by $\alpha$-amylase and also prolongs the intravascular retention time. HESs are identified by three numbers, for example, $10 \%$ HES $200 / 0.5$ or $6 \%$ HES $130 / 0.4$. The first number indicates the concentration of the solution, the second represents the mean molecular weight expressed in kilodalton, and the third and most significant one is molar substitution (MS). High doses of older generation HES solutions with a higher mean molecular weight, a higher degree of MS, and a higher C2/C6 ratio are metabolized and degraded more slowly resulting in a prolonged vascular persistence and potentially a higher incidence of adverse effects on blood coagulation profile and renal function. Modern HES preparations with lower molecular weight and lower MS have not been shown to have any negative influence on kidney function. ${ }^{3}$

There has always been a controversy around the superiority of colloids regarding hemodynamic optimization and about possible detrimental effects on coagulation and renal function as compared to crystalloids. ${ }^{3}$ The safety profile of the newer generation tetrastarches on renal function and coagulation profile has been fairly documented but has not been supported by many studies. Hence, we hypothesized that using tetrastarch (6\% HES 130/0.4) in a single dose may not affect the renal and coagulation profile like the older generation HES products and thus we plan to assess the changes in post-operative renal function and coagulation profile after coloading with $6 \%$ HES 130/0.4 (tetrastarch).

\section{Aims and objectives}

This study aims to study changes in post-operative renal function and coagulation profile.

\section{MATERIALS AND METHODS}

This prospective, randomized study has been conducted after approval from local institutional research and ethical committee and written informed consent from the selected patients who met inclusion criteria. The study is registered with CTRI with reference no. CTRI/2019/08/020890. A total of 70 patients, between the age group of 50 and 80 years of either sex, belonging to ASA Grade I and II scheduled for orthopedic hip surgery under spinal anesthesia were included in the study. Patients belonging to ASA III and IV, patients with chronic kidney disease (estimated GFR $<60 \mathrm{~mL} / \mathrm{min} / 1.73 \mathrm{~m}^{2}$ ), preexisting hematological disease, low platelet count (pre-operative blood count lower than $150 \times 10^{3} \mu \mathrm{L}^{-1}$ ), previous history of hypersensitivity to HES, pre-operative hemoglobin $(\mathrm{Hb})(<10 \mathrm{~g} / \mathrm{dL})$, coagulopathy (previous history or prothrombin time $[\mathrm{PT}]>14 \mathrm{~s}$ ), pulmonary diseases such as pulmonary edema/effusion, and cardiovascular diseases such as coronary artery disease and myocardial infarction, patients with a history of hepatic disease, and patients having a history of long-term intake of nonsteroidal antiinflammatory drugs were excluded from the study. A total of 70 patients ( $\mathrm{n}=35$ per group) reporting in Pt. B. D. Sharma PGIMS, Rohtak, during the proposed time period of study were enrolled in the study. The total sample size was calculated to be 70 ( 35 per group) from an effect size of 0.67 , a power of $80 \%$, an $\alpha$ (level of significance) of 0.05 to detect the difference of 1.0 in renal and coagulation parameters between two groups, based on the study by Zhang et al. ${ }^{4}$

The purpose and protocol of the study were informed to the patient. An informed and written consent to participate in the study was obtained. A detailed clinical history and complete general physical and systemic examination of all the patients were done. Depending on the fluids to be administered, patients were randomly divided in Group HES and ringer lactate (Group RL), and as per the group allocation, coloading was done with $7.5 \mathrm{ml} / \mathrm{kg}$ of either Group RL or 6\% 130/0.4 Group HES during the $1^{\text {st }} \mathrm{h}$ of surgery. Investigations were done on 1 day before surgery, on the day of surgery, and on the $3^{\text {rd }}$ post-operative day. Investigations conducted were - $\mathrm{Hb}$, bleeding time, clotting time, blood urea, serum creatinine, urine output (UO), hematocrit, platelet count, prothrombin time (PT), INR, serum electrolytes $(\mathrm{Na}, \mathrm{K})$, and GFR. GFR estimation was done by Chronic Kidney Disease Epidemiology Collaboration serum creatinine-based equation. ${ }^{5}$

$$
\begin{gathered}
\text { Estimated GFR }=141 \times \min .\left(\mathrm{S}_{\mathrm{CR}} / \mathrm{K}\right)^{\alpha} \times \max . \\
\left(\mathrm{S}_{\mathrm{CR}} / \mathrm{K}\right)^{-1.209} \times(0.993)^{\text {age }} \times(1.018)
\end{gathered}
$$

$\mathrm{K}=0.7$ for females $\quad \alpha=-0.329$ for females

$=0.9$ for males $=-0.411$ for males

Determination of acute kidney injury (AKI) was then done as per Kidney Disease: Improving Global Outcomes (KDIGO) 2012 guidelines. ${ }^{6}$ In the operating room, a standard anesthesia technique was followed for spinal anesthesia by an experienced consultant anesthesiologist ( $>5$ years experience). Routine monitoring was done including heart rate (HR), non-invasive blood pressure, electrocardiography, and pulse oximetry during intraoperative and post-operative time. Intraoperative UO and number of episodes of hypotension and bradycardia were also noted. 


\section{Statistical analysis}

Following observations and results were drawn from the present prospective and randomized comparative study using appropriate statistical tests. The association between categorical explanatory variables and quantitative outcome was assessed by comparing the mean values. The mean differences along with their 95\% CI were presented by independent sample t-test. The change in the quantitative parameters, before and after the intervention was assessed by paired t-test. Odds ratio along with 95\% CI is presented. Chi-square test was used to test statistical significance. $\mathrm{P}<0.05$ was considered statistically significant. IBM SPSS version 22 was used for statistical analysis.

(Machines IB. IBM SPSS Statistics for Windows, Version 22.0. IBM Corp Armonk, NY; 2013.)

\section{RESULTS}

The data of study population including 70 patients were analyzed. Out of 35 people in Group RL, 21 (60\%) participants were male and $14(40 \%)$ participants were female. Out of 35 people in Group HES, 18 (51.43\%) participants were male and 17 (48.57\%) participants were females. Both the groups were comparable with respect to age, sex, weight, height, BMI, and ASA grade. There was no statistically significant difference between both the groups with regard to amount of coload, blood loss, UO, episodes of hypotension, and units of PCV transfused (Table 1).

In our study, it was observed that there was no statistically significant difference in HR over different time intervals in either group. Both the groups were found to be comparable with regard to HR. ( $\mathrm{P}>0.05)$. On comparison of values of systolic blood pressure (SBP), it was observed that in Group RL, there was a statistically significant fall in SBP at $10 \mathrm{~min}, 20 \mathrm{~min}$, and $40 \mathrm{~min}$ as compared to baseline. In Group HES, it was observed that SBP at 10 min interval only was found to be significantly lower than baseline $(* \mathrm{P}=0.015)$. When both the groups were compared with each other, SBP at $20 \mathrm{~min}$ was found to be significantly higher in Group HES ( $\mathrm{P}=0.004)$. Remaining values were not found to be statistically significant (Table 2).

It was observed that the values of hemoglobin and hematocrit on day 1 and day 3 were significantly lower than pre-operative value in both the groups. Although when both the groups were compared with each other, they were found to be comparable with regard to $\mathrm{Hb}$ and Hct. There was no statistically significant difference between groups in platelet count, PT, and INR (Table 3). Both the groups were comparable with respect to blood urea, UO, serum

\begin{tabular}{|c|c|c|c|}
\hline \multirow[t]{2}{*}{ Parameter } & \multicolumn{2}{|c|}{ Groups } & \multirow{2}{*}{$\begin{array}{c}P \\
\text { value }\end{array}$} \\
\hline & $\begin{array}{c}\text { Group RL } \\
(n=35)\end{array}$ & $\begin{array}{c}\text { Group HES } \\
(n=35)\end{array}$ & \\
\hline Age (years) & $60.54 \pm 10.9$ & $65.46 \pm 10.7$ & 0.061 \\
\hline $\begin{array}{l}\text { Gender (M/F) } \\
\text { (Frequency) }\end{array}$ & & 0.470 \\
\hline BMI $\left(\mathrm{kgm}^{-2}\right)$ & $23.51 \pm 2.55$ & $23.34 \pm 2.8$ & 0.786 \\
\hline ASA (1/2) & $11 / 24$ & $6 / 29$ & 0.163 \\
\hline $\begin{array}{l}\text { Duration } \\
\text { of surgery } \\
\text { (hours) }\end{array}$ & $2.59 \pm 0.31$ & $2.49 \pm 0.34$ & 0.233 \\
\hline $\begin{array}{l}\text { Amount of } \\
\text { initial coload } \\
\text { (ml) }\end{array}$ & $471.27 \pm 35$ & $465.62 \pm 36.18$ & 0.510 \\
\hline $\begin{array}{l}\text { Intraoperative } \\
\text { blood loss (ml) }\end{array}$ & $430.14 \pm 111.13$ & $469.71 \pm 129.71$ & 0.174 \\
\hline $\begin{array}{l}\text { Intraoperative } \\
\text { urine output } \\
\text { (ml) }\end{array}$ & $307 \pm 81.08$ & $278.14 \pm 58.78$ & 0.093 \\
\hline $\begin{array}{l}\text { Episodes of } \\
\text { hypotension } \\
(1 / 2)\end{array}$ & $6 / 6$ & $6 / 3$ & 0.553 \\
\hline $\begin{array}{l}\text { Dose of } \\
\text { ephedrine ( } 3 \\
\mathrm{mg} / 6 \mathrm{mg})\end{array}$ & $7 / 6$ & $6 / 3$ & 0.494 \\
\hline $\begin{array}{l}\text { PRBC } \\
\text { transfused (1 } \\
\text { unit/2 units) }\end{array}$ & $10 / 1$ & $14 / 2$ & 0.454 \\
\hline \multicolumn{4}{|c|}{$\begin{array}{l}\text { Age, weight, height, and BMI expressed as mean } \pm \text { SD. SD stands for standard } \\
\text { deviation, P<0.05 considered as statistically significant. Sex, ASA, duration of } \\
\text { surgery, amount of initial coload, intraoperative blood loss, and urine output } \\
\text { expressed as mean } \pm S D \text {. Episodes of hypotension, dose of ephedrine, and units of } \\
\text { PRBC transfused were expressed as frequencies. PRBC: Packed red blood cell, RL: } \\
\text { Ringer lactate, HES: Hydroxyethyl starch solution }\end{array}$} \\
\hline
\end{tabular}

creatinine, and GFR (Table 4 and Figure 1). Furthermore, no patient in our study suffered from AKI of Stages II and III (Table 5 and Figure 2).

\section{DISCUSSION}

Elderly patients are more prone to many iatrogenic complications of major surgery ranging from acute kidney injury to fluid overload and pulmonary edema. ${ }^{2}$ Several renal functional and structural changes like decreased nephron mass have been implicated in this. Therefore, intraoperative optimization of intravenous fluids is of utmost importance in this subset of patients. ${ }^{7}$ Both colloids and crystalloids have been used for this purpose. Crystalloids have potential to cause fluid overload and pulmonary edema if given in large quantities. Colloids provide better hemodynamic stability as compared to crystalloids. ${ }^{8}$ They also have beneficial effects on microcirculation. ${ }^{9}$ Clinicians often use hydroxyethyl starch more than the alternative colloid preparations because of the prolonged and long-lasting volume effect of HES compared to that achieved with crystalloid solutions. Among HES solutions, 6\% HES 


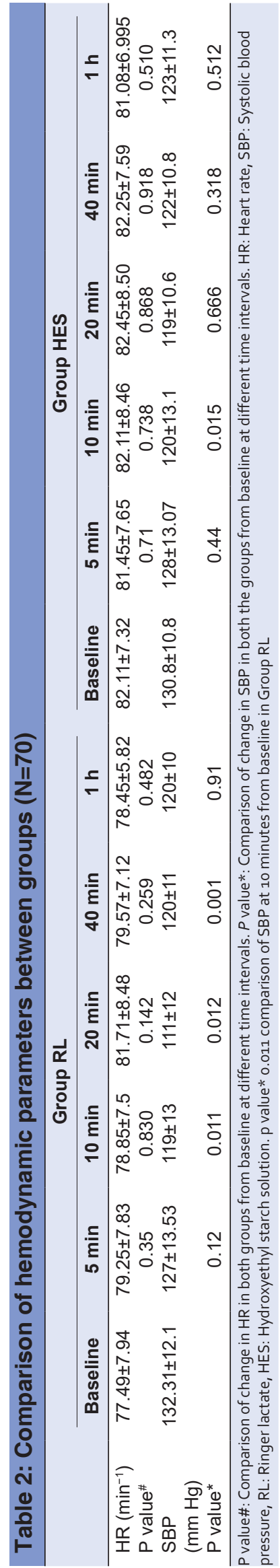

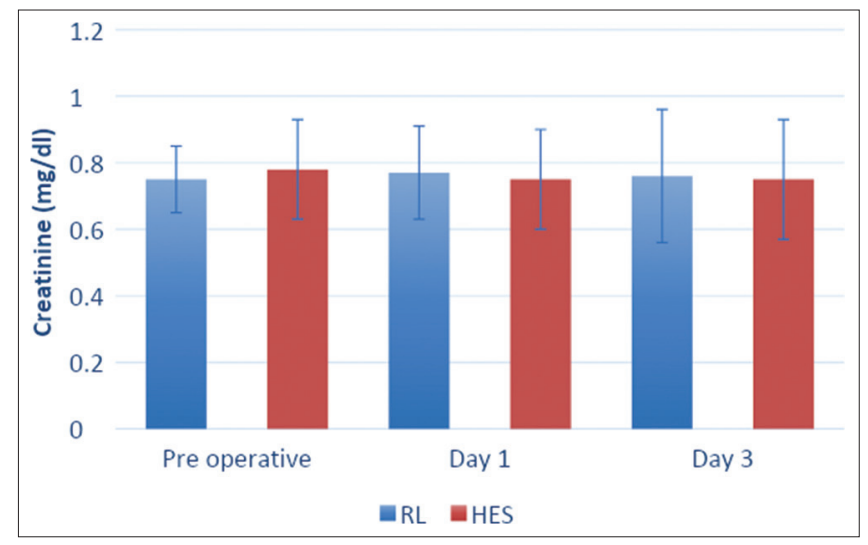

Figure 1: Bar graph with comparison of serum creatinine between groups

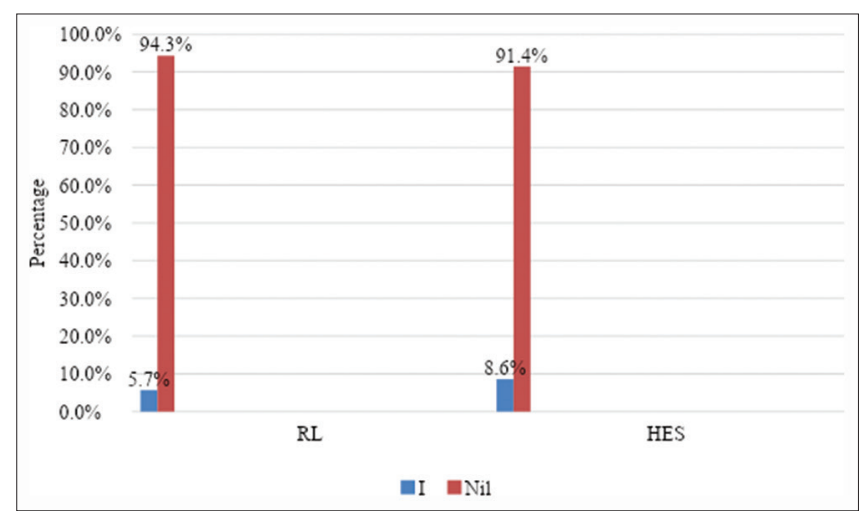

Figure 2: Bar diagram showing occurrence of AKI between groups

$130 / 0.4$ is considered to have the most beneficial effects. ${ }^{3}$ However, over the past decades, several causes of acute kidney failure or osmotic nephrosis like lesions have been reported with the use of colloids. ${ }^{10}$

In our study, among hemodynamic parameters, no statistically significant difference was observed between RL and HES with regard to changes in HR in the intraoperative period. Similar results have also been reported with the study of Zhang et al., who conducted a randomized, double-blinded, placebo-controlled study to investigate whether 6\% HES 130/0.4 administration caused postoperative AKI or not, in elderly patients. ${ }^{4}$ In addition, we observed that intraoperative SBP was better maintained in patients who received HES as compared to RL. The stability in BP in the HES group could be attributed to the improved and sustained hemodynamic stability provided by HES as compared to RL. Results of our study were found similar to studies of Hamaji et al., who conducted a study to compare the effects of HES 130/0.4 to lactated ringer solution during hip arthroplasty in patients scheduled for hip arthroplasty. They also concluded that use of HES leads to better maintenance of blood pressure as compared with crystalloid. ${ }^{11}$ Although, in our study, both groups had 
Kamal, et al.: Changes in post-operative renal function and coagulation profile after hydroxyethyl starch administration in patients undergoing orthopedic hip surgery under spinal anesthesia

Table 3: Comparison of hematological parameters and coagulation profile between groups

\begin{tabular}{|c|c|c|c|c|c|c|c|c|c|c|}
\hline & \multicolumn{3}{|c|}{ Group RL } & \multicolumn{2}{|c|}{$P$ value } & \multicolumn{3}{|c|}{ Group HES } & \multicolumn{2}{|c|}{$P$ value } \\
\hline & Pre-operative & D1 & D3 & $\begin{array}{c}P \\
\text { value\# }\end{array}$ & $\begin{array}{c}\mathbf{P} \\
\text { value* }^{*}\end{array}$ & Pre-operative & D1 & D 3 & $\begin{array}{c}P \\
\text { value\# }\end{array}$ & $\begin{array}{c}\mathrm{P} \\
\text { value*}\end{array}$ \\
\hline $\begin{array}{l}\mathrm{Hb} \\
(\mathrm{gm} / \mathrm{dl})\end{array}$ & $11.80 \pm 1.38$ & $11.80 \pm 1.38$ & $10.17 \pm 1.45$ & 0.006 & 0.0001 & $11.83 \pm 1.36$ & $10.41 \pm 1.52$ & $10.15 \pm 1.43$ & 0.0001 & 0.0001 \\
\hline Hct $(\%)$ & $0.3556 \pm 0.038$ & $0.316 \pm 0.047$ & $0.303 \pm 0.04$ & 0.0004 & 0.0002 & $0.351 \pm 0.04$ & $0.31 \pm 0.045$ & $0.297 \pm 0.04$ & 0.0002 & 0.250 \\
\hline $\begin{array}{l}\mathrm{PC} \\
\text { (lakh/ } \\
\mathrm{mm}^{3} \text { ) }\end{array}$ & $2.89 \pm 0.87$ & $2.79 \pm 0.77$ & $2.87 \pm 0.87$ & 0.581 & 0.90 & $2.65 \pm 0.92$ & $2.65 \pm 0.81$ & $2.76 \pm 0.87$ & 0.989 & 0.63 \\
\hline $\begin{array}{l}\text { PT } \\
\text { (sec) }\end{array}$ & $13.70 \pm 1.8$ & $13.32 \pm 1.90$ & $13.22 \pm 1.81$ & 0.41 & 0.27 & $13.22 \pm 1.56$ & $13.028 \pm 1.55$ & $12.75 \pm 1.55$ & 0.609 & 0.219 \\
\hline INR & $1.06 \pm 0.1$ & $1.035 \pm 0.14$ & $1.054 \pm 0.17$ & 0.436 & 0.80 & $1.04 \pm 0.13$ & $1.02 \pm 0.10$ & $1.28 \pm 0.1$ & 0.434 & 0.52 \\
\hline
\end{tabular}

Table 4: Comparison in parameters of renal function between groups

\begin{tabular}{|c|c|c|c|c|c|c|}
\hline & \multicolumn{3}{|c|}{ Group RL } & \multicolumn{3}{|c|}{ Group HES } \\
\hline & Pre-operative & Day 1 & Day 3 & Pre-operative & Day 1 & Day 3 \\
\hline $\mathrm{BU}\left(\mathrm{mgdl}^{-1}\right)$ & $27.89 \pm 9.44$ & $26.83 \pm 6.77$ & $27.54 \pm 8.16$ & $30.63 \pm 8.81$ & $32.94 \pm 8.70$ & $30.69 \pm 7.33$ \\
\hline UO (ml) & $1500 \pm 185$ & $1444 \pm 138$ & $1510 \pm 171$ & $1484 \pm 222$ & $1394 \pm 187$ & $1447 \pm 212$ \\
\hline$P$ value & & 0.07 & 0.10 & & 0.07 & 0.48 \\
\hline S. Creat $\left(\mathrm{mgdl}^{-1}\right)$ & $0.75 \pm 0.13$ & $0.77 \pm 0.14$ & $0.76 \pm 0.2$ & $0.78 \pm 0.15$ & $0.75 \pm 0.15$ & $0.75 \pm 0.18$ \\
\hline$P$ value & & 0.889 & 0.89 & & 0.747 & 0.850 \\
\hline $\begin{array}{l}\text { GFR } \\
\left(\mathrm{ml} / \mathrm{min} / 1.73 \mathrm{~m}^{2}\right)\end{array}$ & $94.66 \pm 10.79$ & $94.09 \pm 11.05$ & $95.64 \pm 14.72$ & $89.39 \pm 12.97$ & $89.91 \pm 13.88$ & $89.49 \pm 17.01$ \\
\hline$P$ value & & 0.82 & 0.75 & & 0.168 & 0.110 \\
\hline
\end{tabular}

Table 5: Occurrence of AKI between groups

\begin{tabular}{lcccc}
\hline \multirow{2}{*}{ AKI } & \multicolumn{2}{c}{ Groups } & Chi-square & Fisher exact P value \\
\cline { 2 - 3 } & Group RL (N=35) & Group HES (N=35) & \\
\hline Yes (Stage 1) & $2(5.71 \%)$ & $3(8.57 \%)$ & 0.215 & 1.000 \\
No & $33(94.29 \%)$ & $32(91.43 \%)$ & \\
\hline P<0.05 considered as statistically significant, Chi-square. RL: Ringer lactate, HES: Hydroxyethyl starch solution, AKI: Acute kidney injury
\end{tabular}

significant fall of $\mathrm{BP}$ in the first $10 \mathrm{~min}$ as compared to baseline, which could be attributed to hypotension caused by spinal anesthesia.

Both the groups in our study revealed a significant transient decline in hemoglobin and hematocrit values. This could be attributed to the blood loss caused by the surgery and the hemodilution by fluid therapy, respectively. However, none of the groups were found to be superior to the other in terms of hemoglobin and hematocrit values. Our results were found to be consistent with those of Hamaji et al., who too concluded that the initial hemodilution seen with colloids was transient and did not lead to adverse outcomes in the patients. ${ }^{11}$
Among parameters of renal function, both the groups were comparable with each other in serum creatinine, UO, and GFR. Our results came out to be consistent with the studies of Zhang et al., who observed no significant alteration in the levels of creatinine and GFR in both the groups on day 1 and day 3 compared to the baseline. ${ }^{4}$ No significant difference was noted between HES and RL with regard to any change in creatinine from pre-operative value to the post-operative value. Similar results were also observed by Hamaji et al., who did not find any significant difference between serum creatinine values between HES 130/0.4 and RL. ${ }^{11}$ In our study, Stage 1 AKI was seen in $2(5.71 \%)$ patients of Group RL and $3(8.57 \%)$ patients of Group HES. The difference was not statistically significant 
$(\mathrm{P}=1.000)$. No patient in our study suffered from AKI of Stages II and III.

\section{Limitations of the study}

The limitations of our study were use of a fixed dose of HES in elective surgery in a small sample of patients and short follow-up period postoperatively. Moreover, the amount of HES used was also below the maximum recommended dose $\left(50 \mathrm{ml} / \mathrm{kg}\right.$ for $6 \%$ HES 130/0.4). ${ }^{3}$ Recently, more sensitive markers of renal function such as $\alpha-1$ microglobulin and $\mathrm{N}$-acetyl glucosaminidase are being used to determine risk of $\mathrm{AKI}$ in the post-operative period. ${ }^{4}$ Further, we recommend studies with a larger dose and a longer follow-up period to elucidate benefits and complications of tetrastarch in elective surgery, emergency surgery, and critical care settings.

\section{CONCLUSION}

In our study, we found out that both HES and RL were safe to administer for intraoperative fluid resuscitation. There was no statistically significant difference between HES and RL with regard to renal function and coagulation profile. Both HES and RL were comparable in all hemodynamic parameters except BP which was better maintained with HES than RL. To conclude, $6 \%$ HES $130 / 0.4$ in a dose of $7.5 \mathrm{ml} \mathrm{kg}^{-1}$ is safe for intraoperative fluid resuscitation in elderly patients with normal renal function and coagulation profile undergoing orthopedic hip surgery.

\section{ACKNOWLEDGMENT}

We thank Department of Anaesthesiology, Pt. B.D. Sharma PGIMS, Rohtak for their support and cooperation.

\section{REFERENCES}

1. Westphal M, James MF, Langenecker KS, Stocker R, Guidet B and Aken HV. Hydroxyethyl starches: Different products-different effects. Anesthesiology. 2009;111(1):187-202.

http://doi.org/10.1097/ALN.0b013e3181a7ec82

2. Boddaert J, Raux M, Khiami F and Riou B. Perioperative management of elderly patients with hip fracture. Anesthesiology. 2014;121(6):1336-1341. http://doi.org/10.1097/ALN.0000000000000478

3. Mitra S and Khandelwal P. Are all colloids same? How to select the right colloid? Indian J Anaesth. 2009;53(5):592-607.

4. Zhang Y, Yu Y, Jia J, Yu W, Xu R, Geng L, et al. Administration of HES in elderly patients undergoing hip arthroplasty under spinal anesthesia is not associated with an increase in renal injury. BMC Anesthesiol. 2017;17:29-34. http://doi.org/10.1186/s12871-017-0320-8

5. Levey AS, Stevens LA, Schmid CH, Zhang YL, Castro AF $3^{\text {rd }}$, Feldman $\mathrm{HI}$, et al. A new equation to estimate glomerular filtration rate. Ann Intern Med. 2009;150(9):604-612. http://doi.org/10.7326/0003-4819-150-9-200905050-00006

6. KDIGO Clinical Practice Guideline for Acute Kidney Injury. Kidney disease: Improving global outcomes (KDIGO) acute kidney injury work group. Kidney Int. 2012;2:8-12.

7. Anderson S, Eldadah B, Halter JB, Hazzard WR, Himmelfarb J, Home FM, et al. Acute kidney injury in older adults. J Am Soc Nephrol. 2011;22(1):28-38. http://doi.org/10.1681/ASN.2010090934

8. Marino PL. Colloid and crystalloid resuscitation. In: The ICU Book. $4^{\text {th }}$ ed., Ch. 12. New Delhi: Wolters Kluwer; 2014. p. 217-237.

9. Yuruk K, Almac E and Ince C. Hydroxyethyl starch solutions and their effects on the microcirculation and tissue oxygenation. Transfus Altern Transfus Med. 2007;9(3):164-172.

10. Dickenmann M, Oettl T and Mihatsch MJ. Osmotic nephrosis: Acute kidney injury with accumulation of proximal tubular lysosomes due to administration of exogenous salts. Am J Kidney Dis. 2008;51(3):491-503. http://doi.org/10.1053/j.ajkd.2007.10.044

11. Hamaji A, Hajjar L, Caiero M, Almeida J, Nakamura RE, Osawa EA, et al. Volume replacement therapy during Hip Arthroplasty using hydroxyethyl starch (130/0.4) compared to lactated ringer decreases allogeneic blood transfusion and postoperative infection. Rev Bras Anestesiol. 2013;63(1):27-44. http://doi.org/10.1016/S0034-7094(13)70196-X

\footnotetext{
Authors Contribution:

KK - Concept and design of the study, prepared first draft, and supervision; MM - Interpreted the results, reviewed the literature, and manuscript preparation; PB - Concept, coordination, interpretation, and preparation of manuscript, GA - Proofreading and revision of manuscript, RB - Interpretation and revision of manuscript, and DA - Preparation and revision of manuscript, proofreading.

Work attributed to:

Pandit Bhagwat Dayal Sharma Post Graduate Institute of Medical Sciences, Rohtak, Haryana, India.

Orcid ID:

Dr. Kirti Kamal - (1) https://orcid.org/0000-0002-1860-3163

Dr. Monika Bhandari - (1) https://orcid.org/0000-0003-3444-0023

Dr. Priyanka Bansal - (D https://orcid.org/0000-0002-5900-401X

Dr. Geeta Ahlawat - (D https://orcid.org/0000-0002-4986-2002

Dr. Renu Bala - io https://orcid.org/0000-0002-7064-7868

Dr. Diya Aggrawal - (1) https://orcid.org/0000-0002-8287-2325

Source of Support: Nil, Conflicts of Interest: None declared.
} 